\title{
Construction of an economic blanket belt oil skimmer
}

\author{
a Sumon Khandakar, a Md. Nasiqul Islam, ${ }^{\mathrm{b}}{ }^{*}$ Robiul Islam Rubel, ${ }^{\mathrm{b}}$ Sk. Suzauddin Yusuf \\ a Graduate Student, Department of Mechanical Engineering, Rajshahi University of Engineering \& Technology, Rajshahi-6204, Bangladesh \\ b Department of Mechanical Engineering, Bangladesh Army University of Science and Technology, Saidpur Cantonment-5310, Bangladesh
}

A R T I C LE INFO

\section{Article history:}

Received 25 August 2017

Received in revised form 30 November 2017

Accepted 06 December 2017

\section{Keywords:}

Oil spill

Ecology

Skimmer

Blanket belt

\begin{abstract}
AB S T RACT
In this era of modern civilization, liquid fuel transport is mandatory around the world. But there has been several oil spilling accidents around the world and their negative effects are against all the living elements. In the last decades Bangladesh face such problem randomly in sea area and as well as in the river side damaging a large number of livings alongside the river having a badly effect on the entire ecology. The local residents collect the spilled oil manually. The system is less efficient, slow and health hazardous. Belt Oil skimmers using Polymer, Teflon, Elastomer, Corrosion Resistant Steel materials belt are widely used for recovery of this oil. However, they are costly and unavailable. In this work a low cost simple blanket belt skimmer device by using locally available equipment that will be capable to absorb the spilled oil rapidly from river water that is filled with animal and plant waste. After constructing such oil skimmer, the performance is evaluated that accomplish two types of oil having different physical properties. Experimental analysis gives around 190 litre/hour of Sample-1 oil whereas absorption rate for the Sample- 2 oil is around 253 litre/hour for the constructed device with minimum cost compare to the other conventional belt oil skimmer.
\end{abstract}

\section{Introduction}

An oil spill is an incident of accidental or intentional releasing of hydrocarbon, liquid petroleum into the environment, especially marine area contributed by human activity (Li et al., 2012). It is regarded as a practice of pollution. The term "spill" is commonly applied to marine oil spills. Spills may possibly take place on land also. It may occur owe to releases of any kind of oil such as crude petroleum oil from reservoir or transport tankers, drilling wells, rigs, and offshore daises. Dubai government published a technical report on oil spill preparedness and response; provided a several list of oil spill examples and effective responses for recovery [Government of Dubai, 2011). For oil spilling quick response, a mechanical device named skimmer is used to recover or absorb the oil from water surface (Fingas, 2004; Polaris Applied Sciences Inc., 2009). The skimming process is supported by the ASTM

* Corresponding author.

Tel.: +880-1749-399-082

E-mail address: rubel@baust.edu.bd standards for oil spill response equipment (SL Ross Environmental Research Ltd., 2015). Spills may occur from refined petroleum products. Off and on from there by products, and heavier fuels used by large water vessels such as bunker fuel, or the spill of any oily refuse or waste oil. Cleaning and full recovery of spilled oil is challenging and may takes weeks or months. Sometimes even years required to clean up. It depends upon many factors including type of spilled oil, temperature of the water that influences evaporation and biodegradation (Raza et al., 2014). The nature of the shorelines and beaches involved also has a great impact (ITOPF., 2011). Oil spills has disastrous consequences on ecology and economy. Spilling into a marine environment as shown in Figure 1 is subjected to several processes including evaporation, spreading, drifting, dissolution, photolysis, biodegradation and formation of water-oil emulsions (Annunciado et al., 2005). The living animal in the water are the mostly affected by oil. 
Oil simply chokes the animals to death as presented in Figure 2. The birds may have stuck in the thick layer of oil during floating on water and impair its ability to fly (Lim et al., 2013). It can blind an animal. Oil spills sometime causes fire hazard, air pollution, contamination of drinking water supplies who depend on the natural sources. In the year of 2013, Malaysia faces two different oil spills that contaminated water supplies for $3,00,000$ people in Miri, and 80,000 people in Coca Ecuador. In 2,000, spring was contaminated by an oil spill in Clark County, Kentucky (Study Guide, Part III, 2013).

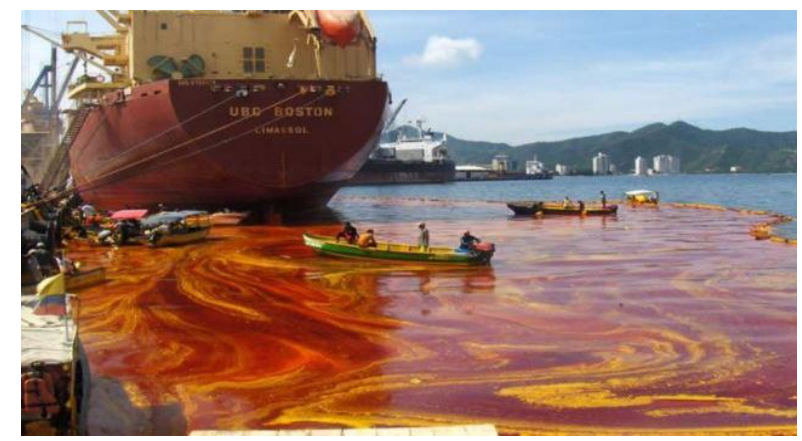

(a)

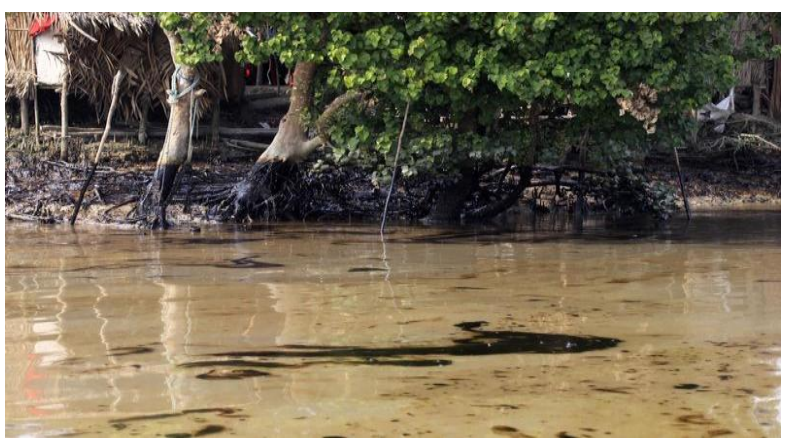

(b)

Figure 1. (a) Oil-spilling in the ocean, (b) Oil spilling in the Shella River, Shundarban, Bangladesh.

The recent major oil spill happened when an oilrig, deepwater horizon sank in the Gulf of Mexico having an economic, commercial effect on tourism, and oceanic resource extraction businesses (NRDC issue paper, 2015; Encyclopædia Britannica News, 2010). In the last five years, all boast economic country like USA, Canada, United Kingdom, Nigeria, China, and France faces the consequence of oil spilling. In Bangladesh recently, several oil spilling incident has occurred near Shundarban (Mangrove Forest in Bangladesh), and coastal area as shown in the Figure 3 (Alexander, 2014; Joint United Nations/ Government of Bangladesh Mission, 2014).

Thus oil cleaning process are mandatory for ecological balance. Therefore, overall objective of that oil spill cleaning operation means treating, recycle or dispose of the greasy, and oily waste in the most effective and environmentally sound manner. The disposal manner must be depended on the amount and type of oil, contaminated rubbish, the geological location of the spill, environmental and legal considerations, and the likely costs involved (IPIECA report series, 2004).

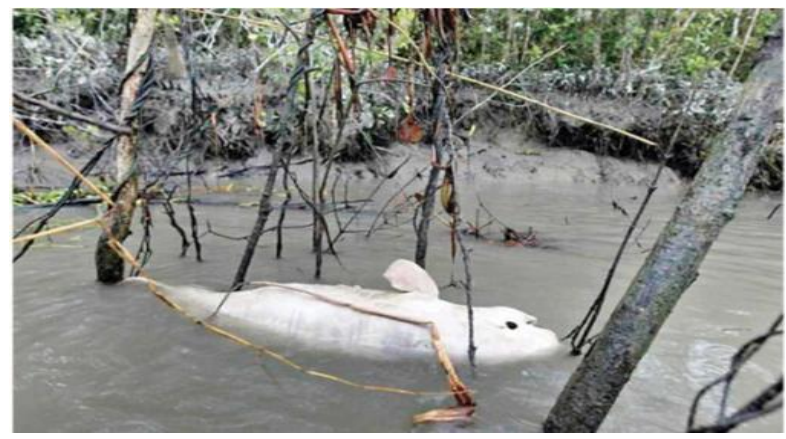

(a)

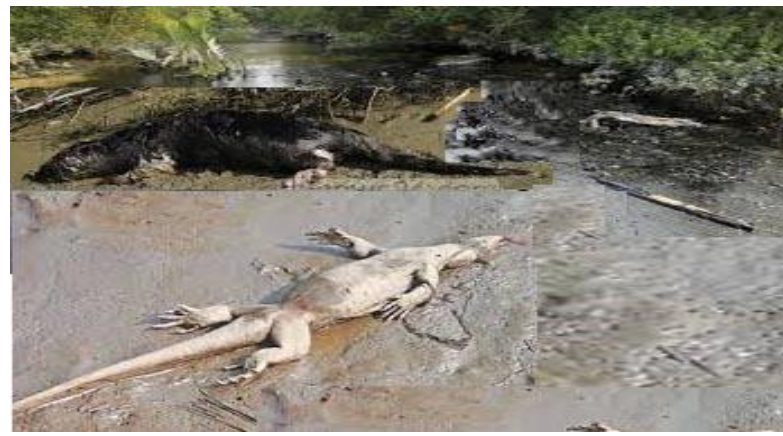

(b)

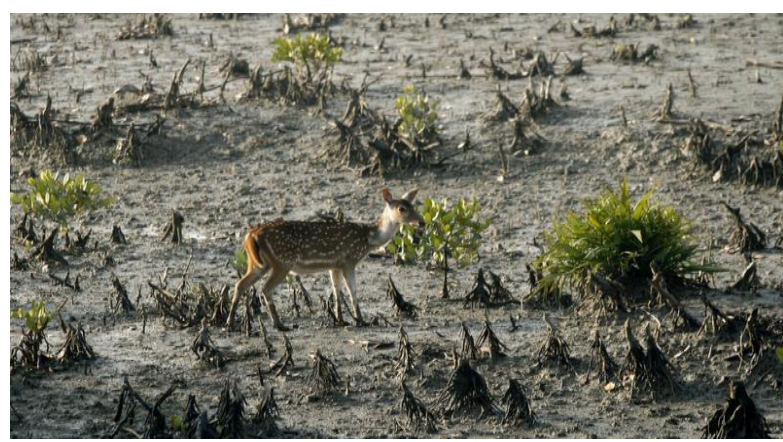

(c)

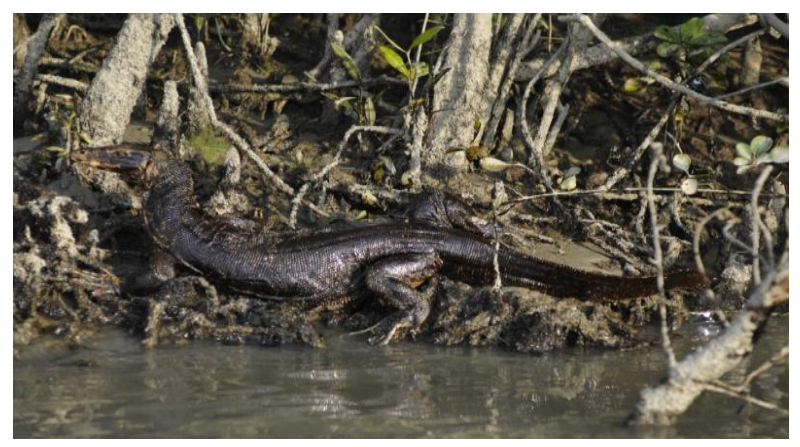

(d)

Figure 2. Death of (a) Dolphin, (b) Crocodile due to oil spilling, (c) Deer, (d) Reptile mudded in oil. 
The oil collection process for those cases is unhealthy and slow involving manual handling that result in health hazardous.

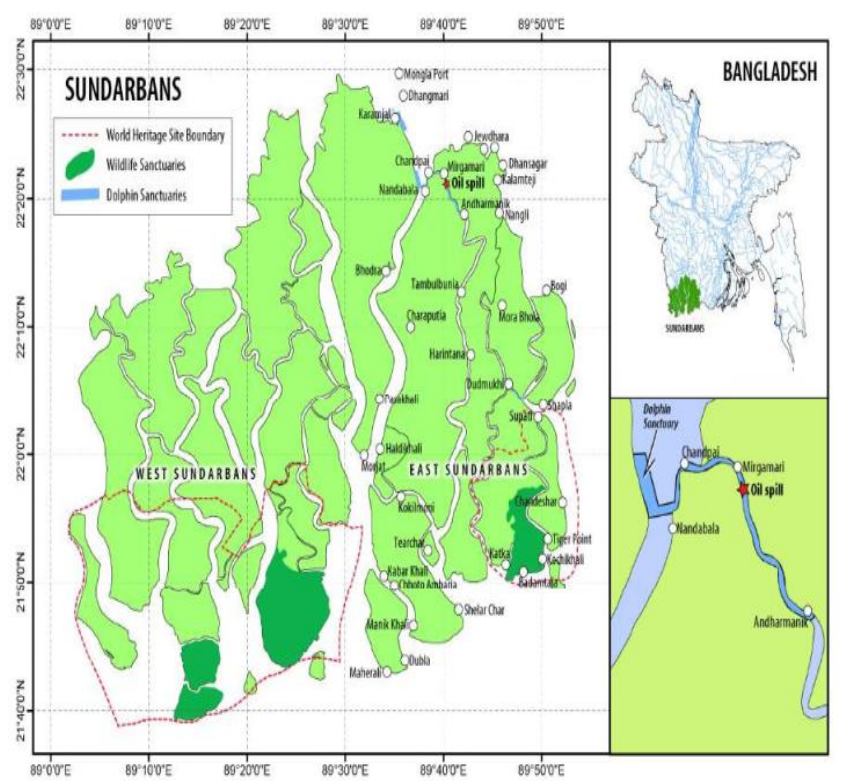

(a)

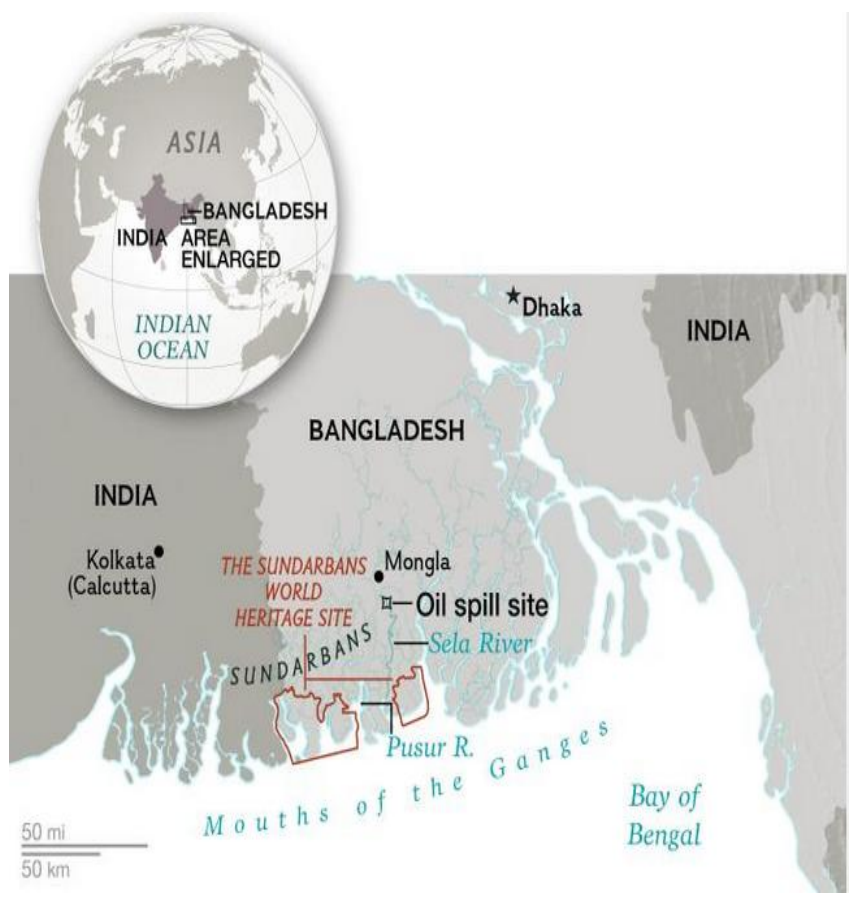

(b)

Figure 3. Map and image showing oil recent spill in Bangladesh. (Source: (a) National Geographic Staff Sources: UNEP-WCMC; ProtectedPlanet.net, (b) Sundarbans oil spill assessment report, 2014).
Some example of manual oil recovery process is presented in Figure 4. If an economic oil absorbing device can be provided among the local residents of the accident spots, then the fast and comparatively safer collection is possible without any post recovery disease.

Researchers are now suggesting the use of locally available resources for oil skimmer (Technical Paper and Circulating Copy of Sea Grant Depository, 1993). In 2015, inventors patented oil-adsorbing blankets (Lacrosse et al., 2015). However, it will extremely effective in removing oil, if used under the correct conditions (Larson, 2010).

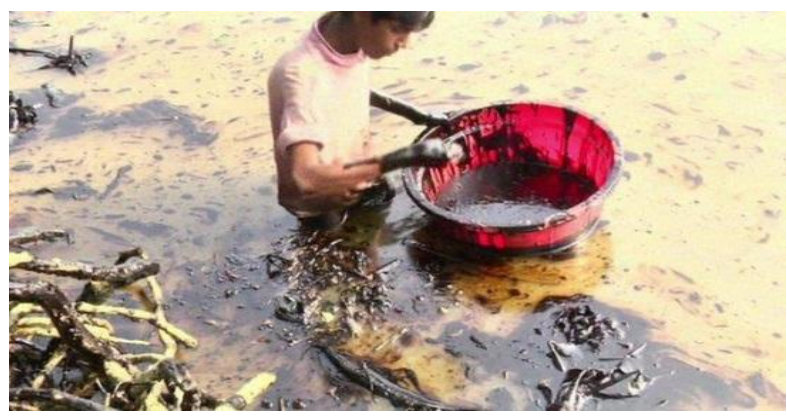

(a)

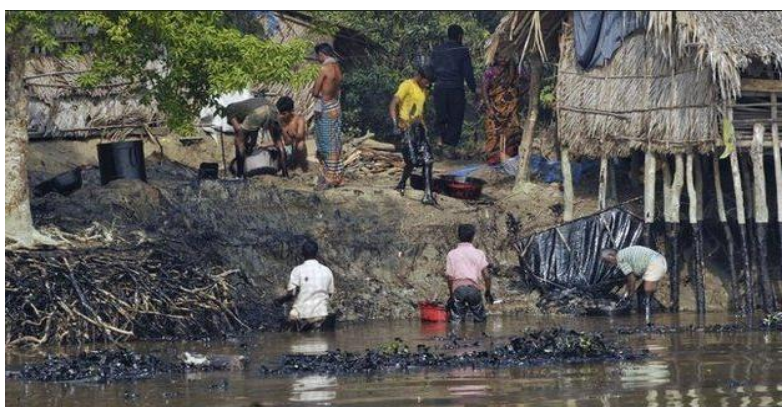

(b)

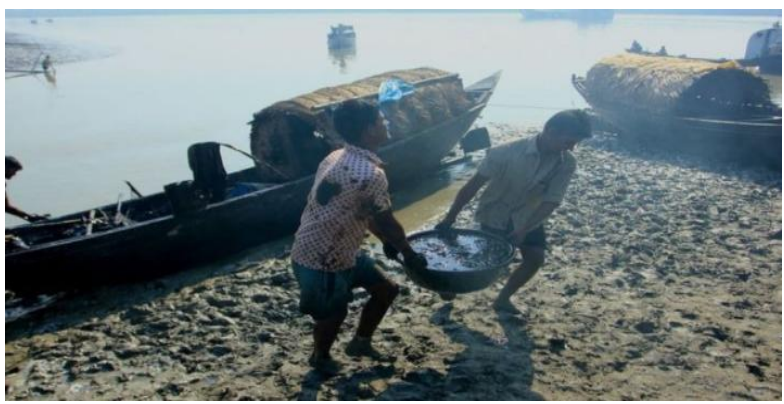

(c) 


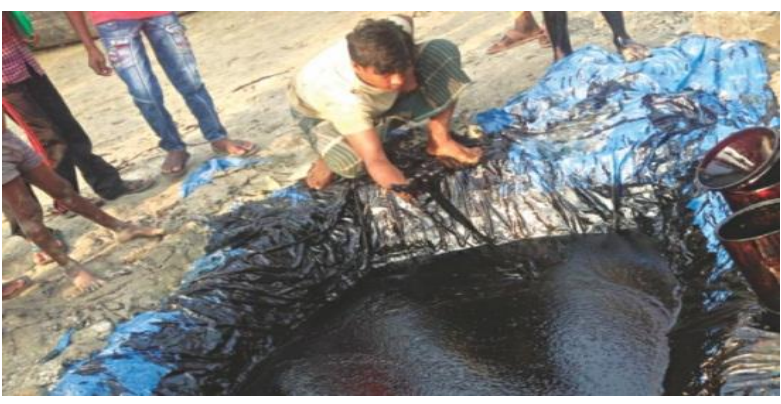

(d)

Figure 4. Local residents manually recovering oil by absorbent materials like straw, jute, clothe etc.

In this work, an attempt has been made to construct such project with locally found material. It is based on without absorbent in the water surface. To construct such oil skimmer Blanket belt has used replacing conventional belt materials. The belt is found appropriate to work in the water that is filled with animal and plant waste. Even no advance knowledge is required for the builder with $1 / 5$ th of cost compare to the oil skimmer that available in the current market around the country. During the problem assessment, tidal conditions has assumed steady except the time of high tide and water is non-salty with normal $\mathrm{pH}$ value.

\section{Literature Review}

A vulnerable damage of ecosystem has done by the several accidents around the world including Bangladesh. Crude petroleum oil or refined fuel spills from carriage ship accidents in Alaska, Mexican gulf, Galapagos Islands, France and numerous other sites. The last accident in Shundarban, Bangladesh in 2014 spreads over $350 \mathrm{Km}^{2}$. Scientists and engineers are continuously trying to find a convenient way to recover the spilled oil. Responding to oil spills immediately is a complex and costly for any significant feasible operation (Ventikos et al., 2004). A varies range of materials for oil remediation have actually been employed such as natural or synthetic dispersants, different absorbents, solidifiers, booms and lastly oil skimmers (Walther III, 2014; Behnood et al., 2013). Dispersants just disperse the oil to quicken the oil separation from the water by absorption.

Absorbents are attractive for applications of collection and complete elimination of oil from the oil spill site (Yang et al., 2016). The application of absorbents to oil spill zones facilitates a change of oil from liquid to semi solid phase. Once this changed is attained, the elimination of the oil by the removal of the absorbents structure becomes easier. About two decades ago, the skimming was $10 \%$ efficient at best (Wadsworth, 1995). Today technology has change and different model of skimmer and sorbent are being tested. Different materials such as Cotton, Steel, Rubber, Polyurethane, Oleophilic are preferred for oil skimming if they have sufficient absorptivity (ITOPF, 2012). Many research and guidelines suggest oil skimming from water surface because of its cost effectiveness and feasibility (Kremer, 2011). Oil skimmers are simple, reliable and effective tools for removing oil, grease and other hydrocarbons from water and coolants. Though Ansell et al. (2001) describes the complexity of heavy fuel skimming, Patel (2015) studies and compares the efficiency of various belt type oil skimmers. Oil skimmer designs vary significantly depending on specific gravity, surface tension and a moving medium to remove floating oil from a fluid surface. Broje et al. (2007) works on the effect of operational parameters on the recovery of an Oleophilic drum skimmer. The work concluded that viscosity, surface tension, oil thickness, temperature and skimmer rotation has immense effect on overall skimming performance. Oleophilic skimmers are constructed on the adhesion of oil to the revolving skimmer surface. The rotating surface lifts the oil out of the water to an oil removal device (Keller et al., 2008).

Researchers work on the application of a number of vegetable fibers as sorbent materials for oil spills (Polaris Applied Sciences Inc, 2009). Hammoud (2001) studied the process of increasing the skimming rare by weir skimming method. Skimming does not change the chemical or physical properties of oil (ITOPF, 1999). Robert W. A. worked on the development of porous free floating endless belt oil skimmer (Agnew, 1972). Lockheed Corporation developed rotating disk oil skimmer (Technical Paper by Abanaki Oil Skimmer). It is capable to skim oil in half-immersed condition. Gupta et al. (2015) describes a hypothesis of eco oil skimmer to increase the oil skimming efficiency up to $60 \%$. Broje et al. (2007) found the effect of contact angles of liquids on solid surfaces. Panditrao (2016) used both belt and disc skimming process for removing oil from seawater for finding the effective method. Pathare et al. (2015) worked on the development of belt skimmer and shows the mathematical design background. Jegele et al. (2016) did the efficiency studies of a belt type oil skimmer conducted by testing six synthetic and six local belt materials in the laboratory.

Dave et al. (2011) found the mechanical method that means skimming is a best remediation process for oil spilling. Sadek Z. K. (Kassab, 2010) also tried to predict the performance of belt skimmer by deducing empirical correlations. Sadek also search the effect of varying the functioning and the environmental parameters. Karan et al. (2011) worked on the application of different structured fabric for oil skimming and concluded that the commercial cotton and natural sorbent can be used for skimming. Husseien et al. (2009) recommends substitution of commercial synthetic oil sorbents in oil spill cleanup by agriculture residue and could be advantageous by incorporating other benefits such as biodegradability.

\section{Methodology and Experiment}

For construction of economic blanket belt oil skimmer two major points is under consideration. First one is the construction of the frame and other relevant structure from locally found materials even from the scrap. That will minimize the cost greatly and low skilled workshop labor can fabricate the model effortlessly. Second is the cost of the belt which is tried to replace by blanket belt instead of 
conventional belt. The proposed belt oil skimmer utilizes a continuous belt with a wiper to remove oil. Instead of conventional costly polymer belt locally found blanket which is used for warming purpose is applied. It is durable fabrics belt able to withstand rough handling during installation and maintenance.

The belt of oil skimming must have the sufficient attraction or affinity for oil than the water. Besides, the durability must be optimistic. Blanket is made from blends of fabrics made of two or more fibers mainly cotton and jute line with polyester or polymer filament. Sometime Jute Blanket is made from the cellulose-rich fiber of the jute plant, which is very common for sub-Indian continent especially in Bangladesh. This belt thus durable for cyclic use and can be applied in the sun for prolong time. The $\mathrm{pH}$ level, saltiness is not so much affecting its performance. Besides this, cleaning is easier and even detergent wash is possible. After being torn and use it can be burn as a domestic fuel. The heat withstand ability is up to $70^{\circ} \mathrm{C}$. Alike the other belt oil skimmer the blanket belt skimmer consists of a motor and pulley system, runs through contaminated liquid. This system picks up oil from the water surface. The differences in specific gravity and surface tension between spilled oil and water helps to attract the oil in the belt. A gear train arrangement is provided for speed control.

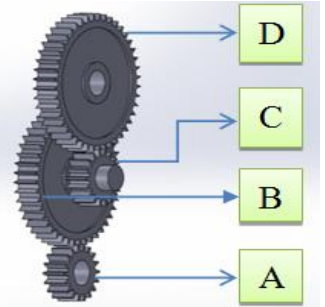

(a)

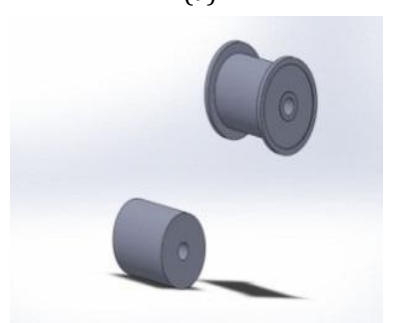

(c)

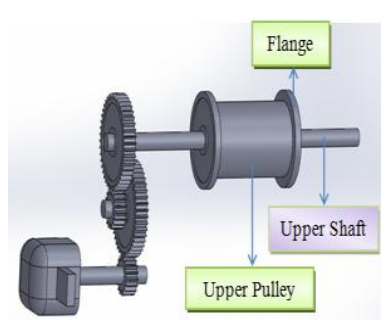

(b)

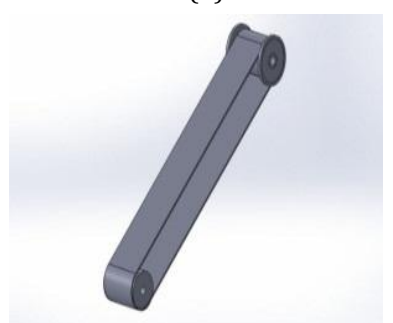

(d)
Figure 5. (a) Designed gear and pinion arrangement (Gear train), (b) Shaft, (c) Upper pulley arrangement with its flanges, (d) Positioning of lower \& upper pulley.

An electrically powered single phase induction motor having $0.5 \mathrm{hp}$ and the max speed of $1490 \mathrm{rpm}$ is used for the project. A gear train as presented in Figure 5(a) achieves low speed of 250-300 rpm as needed. From the given figure, it can be seen that, there is driver wheel $\mathrm{A}$ and driven wheel $\mathrm{D}$ through a compound train B and C. Initially, the speed of a driver wheel A was $1490 \mathrm{rpm}$, which was reduced to $250 \mathrm{rpm}$. Considering reliable power transmission and affinity for oil blanket belt is used for this project. The belt between the flanges in the upper pulley prevents the oil spread out. Now after designing the various parts of the project, they are assembled together in a frame. Therefore, the strength and the rigidity of the designed frame are high enough to withstand with the entire applied load. Usually lower pulley is flange less, because, it is immersed into the oil. The oil is absorbed with the belt from the lower pulley. Afterwards, with the rotation of the shaft, the belt will carry the absorbed oil to the upper pulley. As soon as the belt passes the upper pulley, the tray wipes out the oil from the belt. Inclined belt provides better wiping action.

At the end, the performance of the designed project is estimated and compare with the existing oil skimmer. According to the design, the experimental set-up showing different parts of the project by Figure 6 and Figure 7. The reserve tray is filled with water. The sample oil is poured in the tray. Oil form a layer over the water surface. A blanket piece is cut and sewed as belt. Before first use, oil is spread over the blanket belt to reduce its affinity towards water molecules. As the lower pulley touches the oil, oil is absorbed and the belt wipes the oil in the collector tray. An outlet returns the oil in to the reserve tray. The discharge of the outlet is measure in volume to find the skimming rate. When oil wet the belt slipping may occur. Thus emery paper is provided on the periphery of the pulley to prevent slipping. Physical characteristics of the skimming oil are given in Table 1.

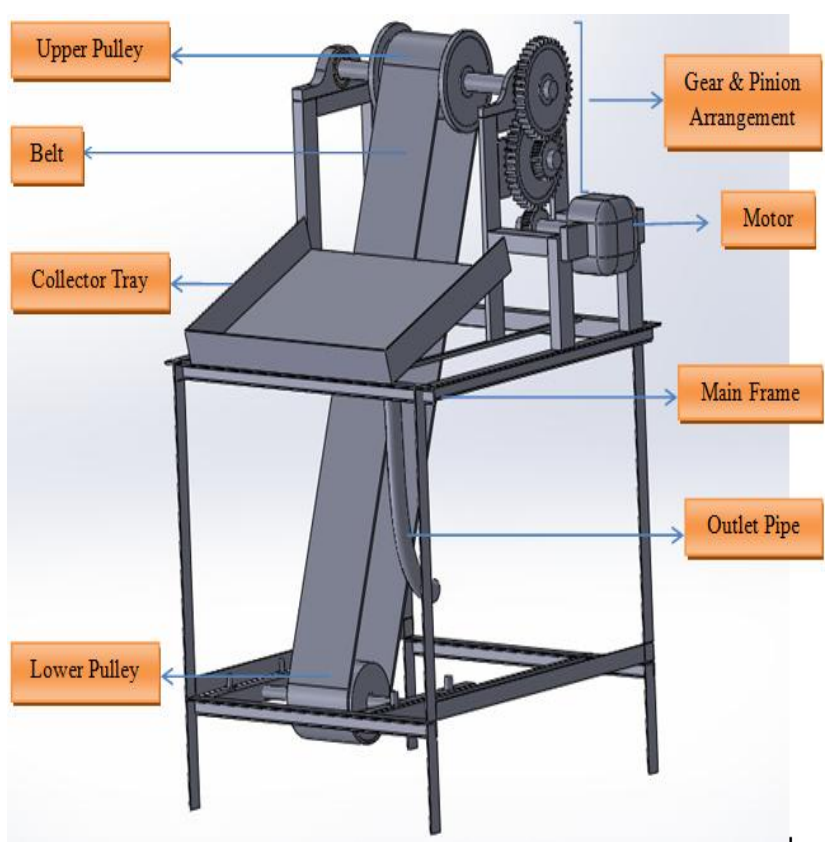

(a) 


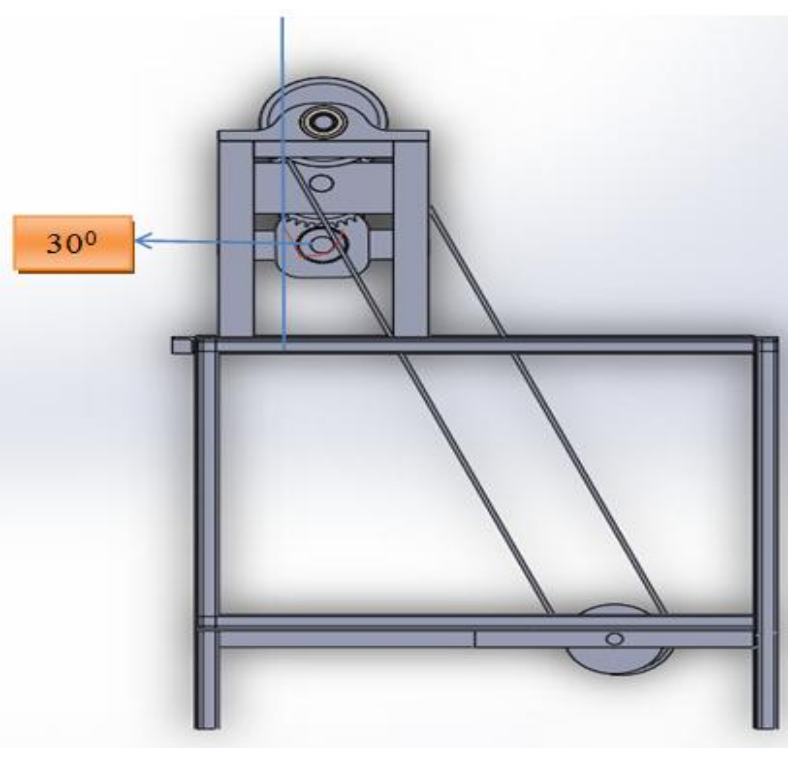

(b)

Figure 6. (a) Isometric view of the design, (b) Oblique view of the designed project showing belt inclination.

Table 1. Properties of the experimental oil

\begin{tabular}{|l|c|c|c|}
\hline \multirow{2}{*}{ Sample } & \multicolumn{3}{|c|}{ Physical Properties } \\
\cline { 2 - 4 } & $\begin{array}{c}\text { Viscosity } \\
\text { (mPa.s) }\end{array}$ & Density (kg/m ${ }^{3}$ ) & Specific Gravity \\
\hline Sample-1 & 310 & 870 & 0.87 \\
\hline Sample-2 & 22 & 710 & 0.71 \\
\hline
\end{tabular}

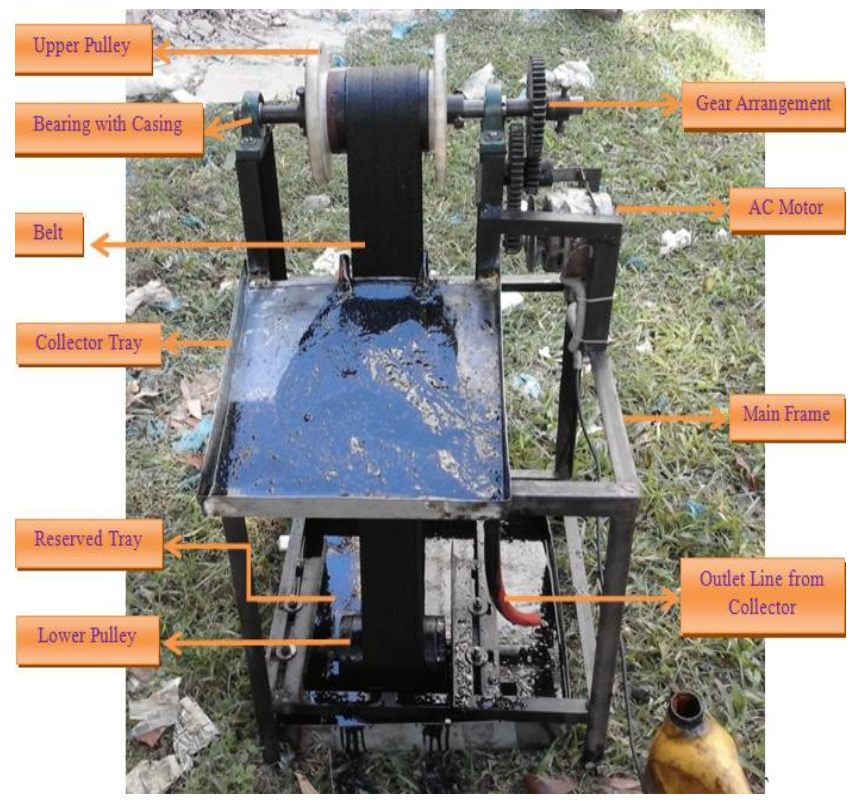

Figure 7. Experimental arrangement for Blanket belt oil skimmer.

\section{Results and Discussion}

The Blanket belt oil skimmer satisfactorily performed the skimming action during test over two oil sample. The absorption rate of the developed Blanket belt oil skimmer varies according to the properties of the oil. The absorption rate for the Sample- 1 is $190 \mathrm{~L} /$ hour and for Sample- 2 is 253 $\mathrm{L} /$ hour. For an hour of motor running $0.5 \mathrm{hp}=(0.5 \times 746)$ Watt or 0.373 Kilowatt electricity is consumed for which cost stands $(0.373$ Unit $\times 5$ BDT/Unit $)=1.865 \mathrm{BDT} /$ hour $(\$ 0.20$ or $€$ 0.19). Therefore, the blanket belt oil skimmer is capable to absorb 1900 litre of Sample-1 and 2530 litre of Sample-2 spilled oil possible to absorb in 10 hours with least amount of cost. The study found around 200-300 L/hour of skimming rate for similar size of belt width in various world-renowned skimmer production companies. The belt reach $\left(36^{\prime}\right)$ is greater for the tested than the conventional skimmer of the similar single belt width. Since the skimming capacity range is around the $200 \mathrm{~L} /$ hour thus the skimmer is in the category of light heavy duty items for viscosity 22-310 mPa.s. With the change of the physical properties, the recovery rate varies significantly. The device is more effective for the absorption of the oil having lower viscosity.

Again, the graph of Figure 8 depicts that for both of the case absorption rate is linear and increase with time and becomes constant at some point. This occurs due to the fact that, belt takes sometimes to get wetted completely and then reach absorption saturation condition. The longevity of the belt is quite long. The blanket fiber is attractive to the water also. But when it is immersed in the oil before first use the sticky ness towards the water molecules drops randomly. However, the affinity towards oil increases due to the cohesive force of oil molecules. This nature provides the opportunity to use it for oil absorption. It is not mandatory to use new blanker for belt purpose; even used items may be applied. For continuous use, the belt required only detergent washing and drying up. Furthermore, the blanket fiber is natural and bio degradable thus after use just burring is required to make it vanish.

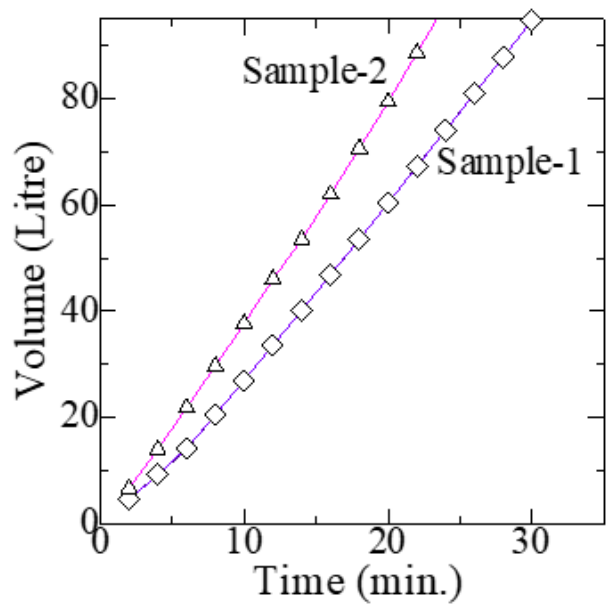

Figure 8. Characteristics curve for (a) Sample -1, (b) Sample - 2. 
Again a simple and anywhere fabric able construction can suit the purpose of that Blanket belt skimmer. These two aspects reduce the construction and maintenance cost of the skimmer.

\section{Conclusions}

Spill prevention is the best possible strategy for oil spill response. The conventional spilled oil removal process is manual. So these are harmful to the human health as well as time consuming. After being concerned with the related problem with the spilled oil and the costly belt oil skimmer, a single Blanket belt economic oil skimmer construction project has performed. Due to the scarcity of the oil skimmer belt replacement materials, locally found new or used blanket that used for warming is employed successfully for recovery of spill oil in an artificial tray model. The work clearly demonstrates that blanket has a miraculous ability to clean up oil spills and its properties must be put into application. The projected oil skimmer belt can skim major portion of oil at steady and gentle flowing water up to $2 \mathrm{~cm}$ layer. Again, the overall cost of the developed project is 10,000 BDT (around \$ 150 or $€ 100$ ) much lower than the existing oil skimmer of $40,000-50,000$ BDT (around \$ 700 or $€ 400$ ).

The replacement of the conventional belt with blanket belt radically lowers the maintenance cost and easy availability. The design and construction of the project is simple thus easy to moderate it for the several conditions as required. According to the volume of the spilled oil, the width and the number of the belt can be re-designed easily to get more absorption. So blanket-belt oil skimmer is economic and feasible for implication. However, several conditions affect the skimming performance. Thus the foregoing recommendation is suggested for future work as given below.

i. The width of belt used in the project is 4.6 inch and the reach of the belt is 38 inch. Belt dimension should vary for high recovery and multi belt project may considered.

ii. Since the oil skimmer is usually portable in nature thus model must be light weighted.

iii. The performance may be considered with varying the motor speed.

iv. In case of turbulence condition, a casing should apply around the lower pulley to get better performance.

v. A skimmer performance is affected by the thickness of the oil layer, weather and emulsification of oil, presence of debris. Thus practical application is necessary before adoption.

vi, The longevity of the Blanket belt will significantly affect the cost.

\section{Acknowledgements}

The authors would like to thank Dr. Mohd. Rafiqul Alam Beg, Professor, Department of Mechanical Engineering from Rajshahi University of Engineering \& Technology, Rajshahi6204 , Bangladesh for his guides during this research.

\section{References}

Annunciado, T. R., Sydenstricker, T. H. D., Amico, S. C., 2005. Experimental investigation of various vegetable fibers as sorbent materials for oil spills. Marine Pollution Bulletin, 50, 1340-1346. doi: 10.1016/j.marpolbul.2005.04.043.

Alexander, C., 17 December 2014. National Geographic Report.

Ansell, D. V., Dicks, B., Guenette, C. C., Moller, T. H., Santne, R. S., White, I. C., 2001. Proceedings from '01: International Oil Spill Conference, The International Tanker Owners Pollution Federation Limited, March 20, Tampa, Florida, USA.

Agnew, R. W., 1972. A free floating endless belt oil skimmer, EPA-R272-006.

Behnood, R., Anvaripour, B., Fard, N. J. H., Farasati, M., 2013. Application of natural sorbents in crude oil adsorption. Iranian Journal of Oil \& Gas Science and Technology, 2(4), 1-11.

Broje, V., Keller, A.A., 2007. Interfacial interactions between hydrocarbon liquids and solid surfaces used in mechanical oil spill recovery. Journal of Colloid and Interface Science, 305, 286-292. doi: $10.1016 /$ j.jcis.2006.09.078.

Broje, V., Keller, A. A., 2007. Effect of operational parameters on the recovery rate of an oleophilic drum skimmer. Journal of Hazardous Materials, 148, 136-143. doi: 10.1016/j.jhazmat.2007.02.017.

Dave, D., Ghaly, A. E., 2011. Remediation technologies for marine oil spills: a critical review and comparative analysis. American Journal of Environmental Science, 7(5), 423-440.

Encyclopædia Britannica News, 2010. Deepwater Horizon oil spill of 2010 (oil spill, Gulf of Mexico). Retrieved from https://global.britannica.com/event/Deepwater-Horizon-oil-spill-of2010.

Fingas, M., 2004. Weather windows for oil spill countermeasures for Prince William Sound Regional Citizens' Advisory Council (PWSRCAC), Anchorage, Alaska, Environmental Technology Centre, Environment Canada.

Government of Dubai, Technical Guideline Number-I., 2011. Oil spill preparedness and response. Marine Environment \& Wildlife Section, Environment Department.

Gupta, U.S., Jain, S., Jain, H., Rathi, S.S., 2015. Experimental performance \& evaluation of eco oil skimmer. International Journal of Research in Engineering Technology and Management, 2 (5), 1-10.

Hammoud, A. H., 2001. Enhanced oil spill recovery rate using the weir skimmer, US EPA Archive Document.

Husseien, M., Amer, A.A., El-Maghraby, A., Taha, N.A., 2009. Availability of barley straw application on oil spill clean-up. International Journal of Environmental Science and Technology, 6(1), 123-130.

ITOPF, 2011. Clean-up of oil from shorelines, Technical Information Paper No. 7, London, UK. Retrieved from https://www.ukpandi.com/fileadmin/uploads/uk-

pi/Knowledge_Base_International_Conventions/TIP\%207\%20Cleanup\%20of\%200il\%20From\%20Shorelines.pdf

IPIECA report series, 2004. Guidelines for oil spill waste minimization and management, Vol. 12, Cedre, UK.

ITOPF, 2012. Use of skimmers in oil pollution response, Technical Information Paper No. 5, London, UK. 
ITOPF, 1999. Use of skimmers in combating oil pollution, Technical Information Paper No. 5, London, UK.

Joint United Nations/Government of Bangladesh Mission, December 2014. Report on: Sundarbans oil spill assessment. Retrieved from whc.unesco.org/document/140155.

Jegele, T. O., Ola, S. A., 2016. Deep groundwater remediation by means of oil skimmer in Baruwa community, Lagos State. International Journal of Environmental Engineering Science and Technology Research, 4(1), 1-11.

Kremer X., 2011. Guidance on Waste Management during a shoreline pollution incident. Operational Guidelines. Brest: Cedre, 83 p.

Keller, A. A., Clark, K., 2008. Oil recovery with novel skimmer surfaces under cold climate conditions, Proceedings from '08: International Oil Spill Conference, USA.

Kassab, S. Z., 2010. Empirical correlations for the performance of belt skimmer operating under environmental dynamic conditions. International Journal of Water Resources and Environmental Engineering, 2(5), 121-129.

Karan, C. P., Rengasamy, R. S., Das, D., 2011. Oil spill cleanup structure fibre assembly. Indian Journal of Fibre \& Textile Research, 36, 190200.

Li, P., Chen, B., Zhang, B., Jing, L., Zheng, J., 2012. A multiple-stage simulation-based mixed integer nonlinear programming approach for supporting offshore oil spill recovery with weathering processes. Journal Ocean Technology, Oil on Water, 7(4), 87-105.

Lim, P., Khimji, K., 2013. The Golden Fleece: Innovative ways to clean up oil. Canadian Young Scientist Journal, 2, 18-23. doi: 10.13034/cysj2013-005.

Larson, H., 2010. Responding to oil spill disasters; ASTM International 2010 WISE Intern.

Lacrosse, J., Baker, J., 2015. Spill removal method and system. United States Patent Application 20150315760, Opflex Technologies.

NRDC issue paper, 2015. Summary of information concerning the ecological and economic impacts of the BP deep water horizon oil spill disaster, IP: 15-04-A.

Polaris Applied Sciences, Inc., 2009. Guidelines and strategies for oil spill waste management in arctic regions, WA 98110-2483, USA.
Patel, M., 2015. Design and efficiency comparison of various belt type oil skimmers. International Journal of Science and Research, 4 (1), 998-1002.

Panditrao, D. D., Jalindar, G. P., Balasaheb, P. K., 2016. Sea oil separator with disc and belt skimmer. International Journal of Scientific Research and Development, 4 (1), 1314-1316.

Pathare, T., Zagade, M., Pawar, R., Patil, P., Patil, A. S., 2015. Endless belt type oil skimmer. International Journal of Recent Research in Civil and Mechanical Engineering, 2 (1), 95-100.

Raza, A., Ge, J., Si, Y., Yu, J., Sun, G., Ding, B., 2014. Applications of electrospun nanofibers in oil spill cleanup. In: Ding B., Yu J. (eds) Electrospun Nanofibers for Energy and Environmental Applications. Nanostructure Science and Technology. Springer, Berlin, Heidelberg, 433-447.

SL Ross Environmental Research Ltd., 2015. Review of ASTM standards for oil spill response equipment. U.S. Department of the Interior, Bureau of Safety and Environmental Enforcement.

Study Guide, Part III., 2013. Proceedings from '13. Topic B: Precaution and response to oil spills. City University of Hong Kong Model United Nations Conference, pp. 11.

Technical Paper and Circulating Copy of Sea Grant Depository, 1993. Surface oil skimmer, NHU-T-93-001 C3.

Technical Paper on Oil Skimmer Facts by Abanaki Oil Skimmer, 1800-358-SKIM (7546).

Ventikos, N. P., Vergetis, E., Psaraftis, H. N., Triantafyllou, G., 2004. A high-level synthesis of oil spill response equipment and countermeasures. Journal of Hazardous Materials, 107, 51-58. doi: 10.1016/j.jhazmat.2003.11.009.

Walther III, H. R., 2014. Clean up techniques used for coastal oil spills: an analysis of spills occurring in Santa Barbara, California, Prince William Sound, Alaska, the Sea of Japan, and the Gulf Coast (Master's dissertation) Paper 104, pp. 6.

Wadsworth, T., 1995. Containment \& recovery of oil spills at sea, methods and limitations. Journal of Waste Management and Environment, 1-4.

Yang, L., Wang, Z., Li, X., Yang, L., Lu, C., Zhao, S., 2016. Hydrophobic modification of platanus fruit fibers as natural hollow fibrous sorbents for oil spill cleanup, Water, Air \& Soil Pollution, 227:346. doi: $10.1007 / \mathrm{s} 11270-016-3043-4$ 